eCommons@AKU

January 2007

\title{
Infective endocarditis in patients with congenitally malformed hearts: characterization of the syndrome in a developing country
}

Bilal K. Siddiqu

M. Tariq

Aga Khan University, muhammed.tariq@aku.edu

AtifJadoon

Ghulam Murtaza

Asim Syed

See next page for additional authors

Follow this and additional works at: https://ecommons.aku.edu/

pakistan_fhs_mc_med_intern_med

Part of the Internal Medicine Commons

\section{Recommended Citation}

Siddiqu, B., Tariq, M., Jadoon, A., Murtaza, G., Syed, A., Abid, M., Qamaruddin, M., Atiq, M., Smego, R. (2007). Infective endocarditis in patients with congenitally malformed hearts: characterization of the syndrome in a developing country. Cardiology in the Young, 17(6), 623-630.

Available at: https://ecommons.aku.edu/pakistan_fhs_mc_med_intern_med/23 
Authors

Bilal K. Siddiqu, M. Tariq, Atif Jadoon, Ghulam Murtaza, Asim Syed, M. Bilal Abid, Maria Qamaruddin, Mehnaz Atiq, and Raymond A. Smego 


\title{
Infective endocarditis in patients with congenitally malformed hearts: characterization of the syndrome in a developing country
}

Bilal K. Siddiqui, Muhammed Tariq, Atif Jadoon, Ghulam Murtaza, Asim Syed, M. Bilal Abid, Maria Qamaruddin, Mehnaz Atiq, Raymond A. Smego

Department of Medicine, Aga Khan University, Karachi, Pakistan

\begin{abstract}
Objective: Cardiac surgery for correction or palliation of congenital cardiac disease in infancy and childhood remains a privilege that is rarely accessible to two-thirds of the world's population. This imbalance has created a unique spectrum of illness in patients with underlying congenital cardiac disease and complicating infective endocarditis in developing countries, including Pakistan. In this study, we characterize endocarditis as seen in such patients presenting in Karachi. Patients and settings: We reviewed retrospectively patients admitted to Aga Khan University with underlying congenitally malformed hearts and endocarditis between 1991 and 2004. Results: We identified 48 patients with endocarditis according to the modified Duke Criterions, with just over half the cases (54\%) classified as definite endocarditis. Of the patients, 23 (49\%) patients were more than 16 years old. Uncorrected left-to-right-shunts, tetralogy of Fallot, and congenital mitral valvar disease were the most common underlying defects. Patients with cyanotic defects, particularly of the complex type, were underrepresented (4\%). Only $11(22.9 \%)$ of the patients had a previous palliative or corrective surgery. In onethird of the patients (16), streptococcal species were identified as the microbiologic cause of endocarditis, and 22 (45.8\%) had culture-negative endocarditis. In contrast, Staphylococcus aureus and enterococci caused endocarditis in only one patient each. There were no differences in mortality or complications between cyanotic and acyanotic congenital defects. Surgery was performed in nine (18.7\%) patients with endocarditis, and of these, $13(27.1 \%)$ died. Conclusions: In contrast to the developed world, endocarditis in the developing countries, such as Pakistan, complicates uncorrected left-to-right shunts and tetralogy of Fallot, probably because patients with complex cyanotic defects fail to survive long after birth due to the lack of available surgery. Almost half of patients had culture-negative endocarditis, likely related to several factors.
\end{abstract}

Keywords: Endocarditis; cyanotic heart defects; acyanotic heart defects; uncorrected congenital heart disease

\section{Introduction}

The prevalence of cardiac malformations is approximately 8 per 1000 live births worldwide. The success of cardiac surgery in the developed world during the last two decades is enormous. A majority of these patients undergoes surgery, with good or satisfying long-term outcomes. With the advent of

\footnotetext{
Correspondence to: Bilal K. Siddiqui MD, Long Island Jewish Medical Center, 270-05 76th Avenue, New Hyde Park, NY 11580. Tel: 1718470 7270; Fax: 1718470 0827; E-mail: bilalkarim81@yahoo.com

Accepted for publication 13 August 2007
}

modern cardiac surgery, even complex forms of congenital cardiac disease may be corrected by a definite or palliative operation. As a number of these patients continue to survive into adolescence and adulthood, congenital defects have become one of the major predisposing factors for infective endocarditis. $^{2}$ In a nation-wide epidemiological study on endocarditis from Netherlands, the underlying predisposition in about one-tenth of patients was a congenitally malformed heart. ${ }^{3}$ Another study of underlying cardiac lesions in adults with endocarditis demonstrated that $13 \%$ had congenital cardiac disease. ${ }^{4}$ This association between congenitally 
malformed hearts and endocarditis remains a lifethreatening handicap for such individuals.

The luxury of early cardiac interventions for congenital cardiac disease in infancy and childhood, nonetheless, remains a privilege that is rarely accessible to those residing in the developing world, accounting for two-thirds of the global population. As a result, many infants with complex defects in developing countries do not see their first birthday. Furthermore, cardiac defects in which the risk of endocarditis could be significantly decreased with corrective surgery, such as ventricular septal defects and persistent patency of the arterial duct, are not submitted for surgical correction. These defects are generally compatible with survival into adolescence, and thus form a large proportion of endocarditis in the setting of congenital cardiac disease in developing countries such as Pakistan. Infective endocarditis in this subset of the population with congenitally malformed hearts, to the best of our knowledge, has not previously been studied from countries in the developing world. In this caseseries, we study specifically endocarditis in patients with congenitally malformed hearts, delineating the underlying predisposing factors, epidemiology, clinical presentation, complications and outcomes in order better to define this clinical entity in a region of the developing world.

\section{Patients and methods}

We reviewed retrospectively the medical records of all patients admitted to Aga Khan University Hospital, Karachi, Pakistan with underlying congenitally malformed hearts and a diagnosis of endocarditis over a period from January, 1991, to December, 2004. The hospital is located in the center of Karachi, a multiethnic city with a population of 15 million, representing all the ethnic subgroups in Pakistan. The population includes a large number of immigrants and referrals from underserved rural areas, where undetected congenital cardiac disease is more common. The median number of admissions during the period was 13,300 patients annually. In this study, we used the revised Duke criterions for the diagnosis of endocarditis to validate our results. ${ }^{5}$ Electronically coded medical records, and the echocardiographic logbook, revealed 188 patients with suspected endocarditis. Of these, 159 patients fulfilled the modified criterions, ${ }^{5}$ and 48 of these $(30.1 \%)$ had an underlying congenitally malformed heart.

Many of the patients had a known congenital defect, while others were diagnosed with congenital cardiac disease after initially presenting with endocarditis. Adults with congenital heart disease were defined as those more than 16 years of age. Fever was defined as a single reading of $38^{\circ} \mathrm{C}$ or more. Patients were classified to have acute endocarditis if they had symptoms for 10 days or less. The number, site, size, and mobility of vegetations, the site and importance of valvar regurgitation, and other valvar injuries such as perforation, abscess, aneurysm, or rupture of tendinous cords, were detailed by transthoracic and transoesophageal echocardiography. Vegetations were defined as localized oscillating masses of dense shaggy echoes that were attached to a valvar leaflet, or to a supporting structure, or in the path of a turbulent jet or on implanted material. A perivalvar abscess was defined as a region of reduced echodensity or echolucent cavity adjacent to the valve or within the valvar annulus. A distinct region of reduced echo density of greater than $5 \mathrm{~mm}$ size inside the ventricular myocardium, detectable throughout the cardiac cycle, was regarded as an intramyocardial abscess. Renal failure was defined by level of creatinine in the serum greater than $2-\mathrm{mg} / \mathrm{dl}$, or a rise over baseline of greater than $1 \mathrm{mg} / \mathrm{dl}$ in patients with chronic renal insufficiency. Nosocomial endocarditis was identified if the patient developed symptoms after 3 or more days of hospitalization for reasons other than endocarditis.

The laboratory workup of these patients included a complete blood count, erythrocytic sedimentation rate, serum creatinine, serum electrolytes, urine analysis and culture, chest X-ray, several blood cultures, with 3 to 5 sets of aerobic and anaerobic bottles inoculated in sterile Bactec Plus ${ }^{\mathrm{TM}}$ bottles (Becton-Dickinson, NJ, USA) drawn before the initiation of antibiotics, transthoracic echocardiography, and if needed, transoesophageal echocardiography. In patients with fever and headache or with neurological signs, examination of cerebrospinal fluids and appropriate imaging were conducted. Fungal cultures were sent in selected cases. The serological tests for Coxiella burnetii, Brucella, and Bartonella were not sent because of financial constraints of the patients and the low clinical index of suspicion. Pakistan is not in the endemic zone for these fastidious organisms, as only a few isolated cases have been reported from northwest of the country. ${ }^{6-8}$

Statistical interpretation of data was performed using the computerized software program SPSS version 13.0 (SPSS, Inc, Chicago, IL, 1999). Descriptive statistics are presented as percentages for discrete variables. Continuous variables are presented as mean plus or minus standard deviations.

Univariate analysis was done for factors associated with mortality and to compare cyanotic and acyanotic heart disease using Pearson Chi Square, 
Fischer Exact Test and Student's t Test where appropriate, and a p value of less than 0.05 was considered statistically significant.

\section{Results}

We found 48 patients with congenitally malformed hearts to have endocarditis according to the modified Duke Criterions ${ }^{5}$ (Table 1). A steady rise in the number of cases was seen over the period of study. Of the 48 patients, 38 (80\%) presented in the second half of the study, from 1999 through 2004. Mean follow-up was two-years and two and a half months, and one patient was lost to follow-up. Antibiotics prior to presentation had been given to 23 patients (48\%), including 2nd and 3 rd generation cephalosporins (40\%), pencillin (20\%), aminoglycosides (30\%) and Amoxicillin in $10 \%$. In $54 \%$ of the patient, the endocarditis was definitive according to the Duke criterions. ${ }^{5}$ Rheumatic heart disease was a concomitant diagnosis in $4(8.4 \%)$ patients. Table 2 gives the distribution of congenitally malformed hearts. Only $11(22.9 \%)$ patients had undergone previous surgery. Patients with cyanotic heart disease were more likely to have positive cultures $(78 \%$ versus $48.7 \%$ ), and had a higher incidence of renal failure (28\% versus $8.3 \%)$ and thrombocytopenia (60\% versus $11.7 \%$, p-value $0.03,95 \%$ CI 1.4-89). There were no differences
Table 1. General characteristics.

\begin{tabular}{|c|c|}
\hline Characteristic & Value \\
\hline Number of patients & 48 \\
\hline Age in years (median \pm Standard Deviation) & $12 \pm 16.7$ \\
\hline $0-6$ years & $14(29.2 \%)$ \\
\hline $7-12$ years & $11(22.9 \%)$ \\
\hline $13-18$ years & $5(10.4 \%)$ \\
\hline $18-30$ years & $8(16.7 \%)$ \\
\hline 31 years and above & $10(20.8 \%)$ \\
\hline Sex (male: female) & $1.8: 1(30 / 18)$ \\
\hline Definite endocarditis ${ }^{1}$ & $26(54 \%)$ \\
\hline Possible endocarditis ${ }^{1}$ & $22(46 \%)$ \\
\hline Nosocomial $^{2}$ & $2(4.1 \%)$ \\
\hline Prosthetic valve endocarditis & $1(2.2 \%)$ \\
\hline Culture negative endocarditis ${ }^{3}$ & $22(45.8 \%)$ \\
\hline Acute endocarditis ${ }^{4}$ & $7(14.6 \%)$ \\
\hline Durations of symptoms in days (median $\pm \mathrm{SD}$ ) & $30 \pm 94$ \\
\hline Follow-up in weeks (mean \pm SD) & $32 \pm 337$ \\
\hline \multicolumn{2}{|l|}{ Predisposing factors } \\
\hline Down's syndrome ${ }^{5}$ & $3(6.3 \%)$ \\
\hline Diabetes Mellitis & $1(2.2 \%)$ \\
\hline Previous endocarditis & $1(2.2 \%)$ \\
\hline $\begin{array}{l}\text { Recent gastrointestinal or genitourinary } \\
\text { manipulation }\end{array}$ & $3(6.3 \%)$ \\
\hline
\end{tabular}

SD Standard deviation, ${ }^{1}$ Modified Duke's criteria, ${ }^{2}>72$ hrs in hospital for reasons other than endocarditis, ${ }^{3}$ At least 2 sets of negative cultures and persistent negative cultures through out the course of endocarditis, ${ }^{4}$ Symptoms of $<10$ days duration, ${ }^{5}$ One patient each had a ventricular septal defect, ASD and a patent arterial duct.

Table 2. Underlying congenital defects.

\begin{tabular}{|c|c|c|c|c|}
\hline Congenital heart disease & $\mathrm{n}(\%)$ & $<2$ years & $2-16$ years & $>16$ years $^{1}$ \\
\hline Cyanotic congenital heart disease & $8(16.7 \%)$ & 2 & 6 & 1 \\
\hline Tetralogy of Fallot & $6(12.5 \%)$ & 1 & 4 & 1 \\
\hline Transposition & $2(4.2 \%)$ & 0 & 2 & 0 \\
\hline Acyanotic congenital heart disease & $40(83.3 \%)$ & 6 & 12 & 21 \\
\hline Ventricular septal defect & $15(31.3 \%)$ & 4 & 5 & 6 \\
\hline Bicuspid aortic valve & $5(10.4 \%)$ & 0 & 0 & 5 \\
\hline Atrial septal defect & $3(6.3 \%)$ & 0 & 1 & 2 \\
\hline Patency of arterial duct & $2(4.2 \%)$ & 1 & 1 & 0 \\
\hline Coarctation of aorta & $2(4.2 \%)$ & 1 & 0 & 1 \\
\hline Congenital mitral regurgitiation & $2(4.2 \%)$ & 0 & 2 & 0 \\
\hline Patent oval foramen & $2(4.2 \%)$ & 0 & 0 & 2 \\
\hline Cleft mitral valve & $1(1.1 \%)$ & 0 & 1 & 0 \\
\hline Congenital mitral stenosis & $1(1.1 \%)$ & 0 & 1 & 0 \\
\hline Supravalvar pulmonary stenosis & $1(1.2 \%)$ & 1 & 0 & 0 \\
\hline Mitral valvar prolapse & $2(4.2 \%)$ & 0 & 1 & 1 \\
\hline Others & $4(8.4 \%)$ & 0 & 0 & 4 \\
\hline Previous surgical correction or palliation & $11(22.9 \%)$ & & & \\
\hline Ventricular septal defect repair & $3 / 12(25 \%)$ & & & \\
\hline Tetralogy of Fallot & $2 / 6(33 \%)$ & & & \\
\hline Transposition & $2 / 2(100 \%)$ & & & \\
\hline Coarctation of aorta & $1 / 2(50 \%)$ & & & \\
\hline Patent arterial duct & $1 / 2(50 \%)$ & & & \\
\hline Atrial septal defect & $1 / 3(33 \%)$ & & & \\
\hline Mean age at surgery & $4.6 \pm 3.5 \mathrm{yrs}$ & & & \\
\hline Surgery for $<2$ yrs & None & & & \\
\hline
\end{tabular}


Table 3. Clinical manifestations and laboratory findings.

\begin{tabular}{lc}
\hline & $\begin{array}{c}\text { Number and percentage } \\
\text { of patients affected }\end{array}$ \\
\hline Signs \& symptoms & \\
Fever & $43(89.6 \%)$ \\
Heart murmur & $41(85.4 \%)$ \\
Splenomegaly & $9(18.8 \%)$ \\
Stroke & $4(8.3 \%)$ \\
Seizures & $4(8.3 \%)$ \\
Systemic embolization & $3(6.3 \%)$ \\
Splinter haemorrhages & $4(8.4 \%)$ \\
Clubbing & $13(27.1 \%)$ \\
Peticheae & $1(2.1 \%)$ \\
Mycotic aneurysm & $1(2.1 \%)$ \\
Laboratory findings & $23(47.9 \%)$ \\
Anaemia & $16(33.3 \%)$ \\
Leukocytosis & $16 / 28(57 \%)$ \\
Elevated ESR & $3(6.3 \%)$ \\
Haematuria &
\end{tabular}

ESR: erythrocyte sedimentation rate; SD: Standard deviation.

between cyanotic and acyanotic defects in terms of death, heart failure, surgery, and complications. Table 3 lists the pertinent clinical and laboratory findings. In one-third (16/48) of our patients, blood cultures were positive for streptococci, while 22 (45.8\%) patients had persistent negative cultures. Table 4 lists the aetiological agents isolated from these patients. Echocardiography was performed in $46(95.8 \%)$ patients, transthoracic echocardiography in $45(93.8 \%)$, and transoesophageal echocardiography in 6 patients $(12.5 \%)$. Transthoracic echocardiogram was positive in 30 of 45 , giving a sensitivity of $67 \%$, and transoesophageal echocardiography was positive in $5 / 6$, with a sensitivity of $87 \%$. The valves involved, and other significant findings on echocardiography, are listed in Table 4.

Most patients were treated with a beta-lactam or vancomycin in combination with gentamicin, depending on the sensitivities, for from 4 to 6 weeks. Surgery was performed in $9(18.75 \%)$ patients, of whom $3(33 \%)$ died. These patients died of sepsis, heart failure, and brain abscess, respectively. None of the organisms were significantly related to surgery. The indications for surgery were heart failure refractory to medical treatment, stroke or peripheral embolism, very large or mobile vegetations, and endocarditis refractory to medical treatment. Of all the patients, $13(27.1 \%)$ died due to endocarditis or one of its complications (Table 5). Table 6 illustrates the factors associated with mortality in these patients. There were no differences in mortality between patients with or without congenitally malformed hearts.
Table 4. Distribution of organisms recovered from blood cultures and echocardiographic findings seen in patients.

\begin{tabular}{|c|c|}
\hline Organism isolated & n $(\%)$ \\
\hline Streptococci & $16(33.3 \%)$ \\
\hline Viridans & $9(18.8 \%)$ \\
\hline Intermedius & $1(2.1 \%)$ \\
\hline Mitus & $1(2.1 \%)$ \\
\hline Others & $5(10.4 \%)$ \\
\hline Staphylococci & $5(10.4 \%)$ \\
\hline Aureus & $1(2.1 \%)$ \\
\hline Coagulase negative & $4(8.4 \%)$ \\
\hline Pseudomonal species & $2(4.2 \%)$ \\
\hline Enterococci & $1(2.1 \%)$ \\
\hline Enterobacter & $1(2.6 \%)$ \\
\hline Serratia & $1(2.1 \%)$ \\
\hline No growth ${ }^{1}$ & $22(45.8 \%)$ \\
\hline \multicolumn{2}{|l|}{ Location on echocardiography ${ }^{2}$} \\
\hline Aortic valve & $11(22.9 \%)$ \\
\hline Ventricular septal defect & $9(18.9 \%)$ \\
\hline Mitral valve & $9(18.9 \%)$ \\
\hline Pulmonary valve & $4(8.4 \%)$ \\
\hline Tricuspid valve & $6(12.5 \%)$ \\
\hline Patent arterial duct & $2(4.2 \% \%)$ \\
\hline Atrial septal defect & $1(2.1 \%)$ \\
\hline Coarctation of aorta & $1(2.1 \%)$ \\
\hline Pulmonary arteries & $1(2.1 \%)$ \\
\hline Normal & $8(16.8 \%)$ \\
\hline Right-sided endocarditis & $13(27.1 \%)$ \\
\hline \multicolumn{2}{|l|}{ Character } \\
\hline Vegetations & $27(56.3 \%)$ \\
\hline Mobile vegetations & $11(22.9 \%)$ \\
\hline Large vegetation ${ }^{3}$ & $9(18.8 \%)$ \\
\hline Valvar abscess & $1(2.1 \%)$ \\
\hline Multiple valves/locations & $5(10.4 \%)$ \\
\hline \multicolumn{2}{|l|}{ Regurgitation $^{4}$} \\
\hline Aortic & $11(23 \%)$ \\
\hline Mitral & $9(18.8 \%)$ \\
\hline Tricuspid & $12(25.1 \%)$ \\
\hline
\end{tabular}

${ }^{1}$ At least 2 sets of negative cultures and persistent negative cultures through out the course of endocarditis, ${ }^{2}$ Includes multiple vegetation/abscesses, ${ }^{3}$ Size $>10 \mathrm{~mm},{ }^{4}$ Moderate to severe regurgitation.

\section{Discussion}

Our study, to the best of our knowledge, represents one of the first case-series of endocarditis in patients with congenitally malformed hearts from the developing world. Most of the patients had uncorrected malformations, such as ventricular septal defect, tetralogy of Fallot, atrial septal defect, persistent patency of the arterial duct, congenital mitral valvar disease, and aortic coarctation. In contrast, approximately $70 \%$ of children with endocarditis complicating congenital cardiac disease in the developed world have had previous cardiac surgery, particularly palliative shunt procedures and complex intracardiac repairs. ${ }^{9,10}$ Nearly one-third to half of all these defects are critical, requiring intervention in the first year of life. ${ }^{11}$ With currently available modalities for 
Table 5. Complications and mortality observed in patients with infective endocarditis.

\begin{tabular}{lc}
\hline Complications & $\mathrm{n}(\%)$ \\
\hline Death & $13(27.1 \%)$ \\
Surgery needed & $9(18.8 \%)$ \\
Neurological complications & $12(25 \%)$ \\
$\quad$ Stroke & $4(8.3 \%)$ \\
Intracanial haemorrhage & $2(4.2 \%)$ \\
Seizures & $4(8.3 \%)$ \\
Meningitis & $1(2.1 \%)$ \\
Brain abscess & $1(2.1 \%)$ \\
Renal complications & $5(10.4 \%)$ \\
Renal failure & $5(10.4 \%)$ \\
Glomerulonephritis & $1(2.1 \%)$ \\
Interstitial nephritis & $1(2.1 \%)$ \\
Hemolysis & $4(8.3 \%)$ \\
Cardiac & \\
Heart failure & $13(27.1 \%)$ \\
Cardiac abscess & $1(2.1 \%)$ \\
Valvular insufficiency & $21(43.8 \%)$ \\
Peripheral embolism & $3(6.3 \%)$ \\
Mycotic aneurysm & $1(2.1 \%)$ \\
Pneumonia & $5(10.4 \%)$ \\
Sepsis & $1(2.1 \%)$ \\
\hline
\end{tabular}

${ }^{1}$ Defined as serum creatinine level $>2 \mathrm{mg} / \mathrm{dl}$ or a rise over baseline creatinine of $>1 \mathrm{mg} / \mathrm{dl}$ in patients with chronic renal insufficiency.

treatment, over three-quarters of infants born with critical cardiac disease can survive beyond the first year of life, and many can lead near-normal lives thereafter. This privilege of early diagnosis and timely management is restricted to children and adolescents of the developed countries. The majority of children born with congenitally malformed hearts in developing countries do not get the necessary care, resulting in a high morbidity and mortality. Only one-fifth of the patients seen in our study had undergone a previous cardiac repair or palliation. Previous studies on endocarditis in children from the developing world have shown that less than one fifth of those with congenitally malformed hearts have had a previous surgical repair or palliation. ${ }^{12-17}$ Congenital cardiac diseases in developing countries remain undiagnosed and under-treated. $^{18-21}$

Patients with cyanotic heart disease, particularly of the complex type, were underrepresented in our study. These patients usually do not survive without surgery, while repair, insertion of prosthetic material, or palliation leads to a very high annual risk for endocarditis. ${ }^{22,23}$ Cyanotic heart defects as an underlying predisposition for endocarditis in the United States increased from less than $20 \%$ in 1950 s to $45 \%$ by the 1970 s. ${ }^{10}$ As a large majority of patients with complex cyanotic heart disease never survive to childhood, or even infancy, in most of the developing world, these lesions constitute only one-fifth or less of those with endocarditis and congenital cardiac disease. ${ }^{12-17,24,25}$ Of those with cyanotic diseases, tetralogy of Fallot constitutes three-quarters of the patients in our series. The other two patients with complex cyanotic heart disease had transposition, and had undergone surgical repair in infancy. This emphasizes the fact that survival of patients with complex cyanotic heart diseases without corrective surgery is dismal. Tetralogy of Fallot represents an exception among cyanotic heart diseases, as children with this condition can survive several years without surgery. In fact, some patients may go unrecognized till late in infancy, and present with endocarditis in childhood. Only one-third of the patients with tetralogy of Fallot in our series had undergone surgical correction. Recent studies have shown that tetralogy of Fallot is now a rare cause of endocarditis in both children and adults in the developed world. ${ }^{26}$ Complete closure of the ventricular septal defect associated with tetralogy of Fallot, eliminating the systemic-to-pulmonary shunt, minimizes the susceptibility to endocarditis. ${ }^{22,23}$

Left-to-right shunts, particularly in those with uncorrected ventricular and atrial septal defects and arterial ducts, are the most common underlying defects seen in our series. This trend is similar to the experience in the developed world prior to the emergence of definitive surgery. High-velocity or turbulent flow caused by the high pressure leftsided circulation causes endocardial damage, and creates a nidus for subsequent bacterial colonization and endocarditis. Early detection and surgical repair has lead to a decline in the importance of leftto-right shunts as sites of bacterial endocarditis in the developed world. ${ }^{9-11}$ Complete surgical repair eliminates, or markedly decreases, the risk of endocarditis in these patients. ${ }^{27}$ Of a large cohort seen in a community-based 30-year study, none of the patients with a definitively corrected ventricular septal defect developed endocarditis. ${ }^{22}$ Without surgical repair, nonetheless, these patients are at high risk for endocarditis, with an incidence of $1.1 \%$ at 5 years of age or an overall risk of 3.8 cases per 1000 patient-years. ${ }^{22}$ As a result ventricular septal defect now constitutes less than one-fifth of those with endocarditis in the developed world. ${ }^{9,10}$ On the other hand, ventricular septal defect is the most common underlying congenital anomaly seen in both adults and children in our series. Of these, four-fifths had not undergone prior surgical correction. A similar trend is seen in the rest of the developing world, where ventricular septal defect accounts for almost half of congenital defects in children with endocarditis, ${ }^{12-17,24,25}$ of whom only 5 to15\% had undergone prior surgical repair. 
Table 6. Risk factors for mortality in patients with Infective endocarditis and congenital heart disease.

\begin{tabular}{|c|c|c|c|c|}
\hline Variable & Dead & Alive & $\mathrm{p}$ value & CI at $95 \%$ \\
\hline \multicolumn{5}{|l|}{ General characteristics } \\
\hline Age $($ mean $\pm S D)$ & $22.5 \pm 18$ & $16.7 \pm 16$ & $\mathrm{NS}^{1}$ & $0.5-16$ \\
\hline Sex (male) & 7 & 23 & NS & $0.17-2.2$ \\
\hline Acute endocarditis & 6 & 9 & NS & $0.63-9$ \\
\hline Culture positive endocarditis & 7 & 19 & NS & $0.27-3.5$ \\
\hline Definitive endocarditis & 6 & 20 & NS & $0.17-2.3$ \\
\hline Nosocomial & 2 & 0 & $0.06^{2}$ & $2.5-7.0$ \\
\hline \multicolumn{5}{|l|}{ Presentation } \\
\hline Fever & 12 & 31 & NS & $0.15-15.2$ \\
\hline Splenomegaly & 2 & 7 & $\mathrm{NS}^{2}$ & $0.13-4.6$ \\
\hline Anemia & 7 & 16 & NS & $0.39-5$ \\
\hline Thrombocytopenia & 1 & 6 & $\mathrm{NS}^{2}$ & $0.045-4.05$ \\
\hline Lekocytosis & 4 & 12 & $\mathrm{NS}^{2}$ & $0.21-3.3$ \\
\hline Clubbing & 6 & 7 & NS & $0.87-13.5$ \\
\hline \multicolumn{5}{|l|}{ Predisposing factors } \\
\hline Cyanotic heart disease & 3 & 6 & $\mathrm{NS}^{2}$ & $0.3-6.9$ \\
\hline Ventricular septal defect & 2 & 13 & $\mathrm{NS}^{2}$ & $0.05-1.6$ \\
\hline Previous cardiac surgery & 5 & 7 & NS & $0.62-10$ \\
\hline Prosthetic valvar endocarditis & 1 & 0 & $\mathrm{NS}^{2}$ & $0.79-1.08$ \\
\hline \multicolumn{5}{|l|}{ Microbiology } \\
\hline Streptococci & 3 & 13 & $\mathrm{NS}^{2}$ & $0.12-2.2$ \\
\hline Pseudomonas spp. & 2 & 0 & $0.06^{2}$ & $2.5-7.0$ \\
\hline \multicolumn{5}{|l|}{ Complications } \\
\hline Neurological complications & 3 & 9 & $\mathrm{NS}^{2}$ & $0.19-3.8$ \\
\hline Renal failure $^{3}$ & 2 & 3 & $\mathrm{NS}^{2}$ & $0.29-13.2$ \\
\hline Hemolysis & 1 & 3 & $\mathrm{NS}^{2}$ & $0.08-9.4$ \\
\hline Peripheral embolism & 1 & 2 & $\mathrm{NS}^{2}$ & $0.085-13$ \\
\hline Heart failure & 9 & 4 & $<0.001^{2}$ & $3.6-84$ \\
\hline Large vegetation ${ }^{4}$ & 4 & 5 & $\mathrm{NS}^{2}$ & $0.6-12$ \\
\hline Mobile vegetation & 3 & 8 & $\mathrm{NS}^{2}$ & $0.223-4.6$ \\
\hline Multiple valves & 2 & 3 & $\mathrm{NS}^{2}$ & $0.29-13.2$ \\
\hline Pneumonia & 3 & 2 & $\mathrm{NS}^{2}$ & $0.72-34$ \\
\hline Sepsis & 1 & 0 & $\mathrm{NS}^{2}$ & $0.79-108$ \\
\hline Surgery for endocarditis & 3 & 6 & $\mathrm{NS}^{2}$ & $0.27-6.2$ \\
\hline
\end{tabular}

NS: Not Significant; SD: Standard deviation. ${ }^{1}$ Student's t-test, ${ }^{2}$ Fischer Exact Test, ${ }^{3}$ Defined as serum creatinine level $>2 \mathrm{mg} / \mathrm{dl}$ or a rise over baseline of $>1 \mathrm{mg} / \mathrm{dl}$ in patients with chronic renal insufficiency, ${ }^{4}$ Size $>10 \mathrm{~mm}$.

In 2 of our patients, infective endocarditis developed in the setting of an underlying patent arterial duct. A recent study from northern Pakistan reported that infective endocarditis of patent arterial duct might be very common. ${ }^{28}$ This high incidence of infective endocarditis in patients with patent arterial duct is unusual, and represents something close to the natural history of uncorrected patent arterial duct, ${ }^{29}$ as suture ligation of patent arterial duct completely eliminates the risk of endocarditis. Infective endarteritis of patent arterial duct is now extremely rare in most parts of the world. 9,11,30 $^{-1}$

More than one-tenth of our patients had a bicuspid aortic valve. The natural history of a bicuspid valve is premature calcification, which occurs in nearly all individuals aged 40 years, with subsequent possibility of progression to aortic stenosis. Endocarditis is a well-recognized complication, usually occurring in the fourth and fifth decades of life, as in our series. Most data from the developed $^{4,31}$ and developing world ${ }^{32}$ reports that bicuspid aortic valve may be the underlying cause for up to one-sixth of patients with native valvar endocarditis. This entity is considered to be the most common congenital cardiac lesion seen at autopsies. ${ }^{33}$

Neonates, infants and young children undergoing palliative or corrective surgery currently represent the largest group of children at risk of endocarditis in most of the developed world. It should be emphasized that the increase in overall incidence of endocarditis is largely due to a greater frequency of the disease among the neonates and children under 2 years of age, as seen in our series. On the other hand, our series also has a large proportion of adults more than 16 years. As more patients with these defects are reaching adulthood, the number of cases of endocarditis in adults with congenitally malformed hearts has increased. ${ }^{34}$

Boys outnumber girls in our series. This is in contrast to most of the data worldwide, except 
South Asia. ${ }^{24,25,33}$ This may be because of bias on behalf of parents in South Asia to favour the male child over the female. Males are better cared for, and taken to the hospital more frequently for treatment. On the other hand, many girls in South Asia with life-threatening diseases, such as congenitally malformed hearts, are generally left to the "will of God" to suffer a natural course of events, and never make it to the hospital.

Both patients with nosocomial endocarditis in our series died. Nosocomial endocarditis is usually associated with a structurally normal heart, and occurs in the setting of surgical procedures or use of intravenous catheters. ${ }^{35}$ The high mortality in our patients is consistent with worldwide data, where nosocomial endocarditis carries a mortality of more than half. In a recent series from Madrid, nosocomial infection accounted for endocarditis in over one-fifth of patients, and resulted in more than half dying. ${ }^{36}$

We see a lot of patients with endocarditis and negative cultures. The high ratio of negative cultures is not unusual for developing countries, and has been found in up to three-fifths. ${ }^{24,25}$ The most common important cause of such a high ratio of culture-negative endocarditis is prior use of antibiotics without appropriate workup, as seen in half of our patients.

Mortality of endocarditis seen in our series is much higher than most of the developed world, where it is generally between 5 and $20 \%$. We are a tertiary care referral centre, and these results may represent a skewed population. This high mortality can be attributed to late presentation, prior use of antibiotics causing negative cultures with subsequent late diagnosis, and advanced underlying cardiac diseases such as severe pulmonary hypertension. It is important to note that patients from developed countries with endocarditis are already high risk because of more complex congenital heart diseases. Many of these children have already undergone multiple cardiac surgeries before presentation, and more frequently acquire nosocomial endocarditis, which carries a grave prognosis. Despite these predisposing factors for endocarditis in the developed world, the comparatively higher mortality seen in this series further emphasizes the need aggressively to treat and prevent endocarditis in Pakistan.

Our study has several limitations. First, the retrospective nature of the study does not allow for control of data and requires cautious interpretation of the results. Serology and polymerase chain reaction for fastidious organisms such as Brucella, Bartonella, Coxiella burnetii, and other rare causes of endocarditis were not sent, and thus we may have missed some patients with culture-negative endocarditis. Being a tertiary care private referral center, the data may not truly represent endocarditis in the community, and may be skewed towards a high-risk patient and wealthier population. Our study was not adequately powered to identify risk factors for mortality because of the small size of the sample. Many of the patients received prior antibiotics, and thus the 'true' microbiology cannot be ascertained. The series most likely underestimates the true incidence of endocarditis, given the limitations in microbiologic detection of the cause of endocarditis. Further prospective studies are needed to confirm our results.

\section{References}

1. Hoffman JI, Christianson R. Congenital heart disease in a cohort of 19,502 births with long-term follow-up. Am J Cardiol 1978; 42: 641-647.

2. Korzeniowski OM, Kaye D. Infective endocarditis. In: Braunwald E. (ed). Heart disease: a textbook of cardiovascular medicine. Saunders, Philadelphia, 1992, pp 1078-1105.

3. Van der Meer JT, Thompson J, Valkenburg HA, Michel MF. Epidemiology of bacterial endocarditis in The Netherlands. II. Antecedent procedures and use of prophylaxis. Arch Intern Med 1992; 152: 1869-1873.

4. McKinsey DS, Ratts TE, Bisno AL. Underlying cardiac lesions in adults with infective endocarditis. The changing spectrum. Am J Med 1987; 82: 681-688.

5. Li JS, Sexton DJ, Mick N, et al. Proposed modifications to the Duke criteria for the diagnosis of infective endocarditis. Clin Infect Dis 2000; 30: 633-638.

6. Ahmed IP. A serological investigation of $\mathrm{Q}$ fever in Pakistan. J Pak Med Assoc 1987; 37: 126-129.

7. Servino V, Assuma M, De Dominicis A. Serum antibodies against adenoviruses, reoviruses and Coxiella burnetii in subjects of Swat (northwestern Pakistan). Arch Ital Sci Med Trop Parassitol 1968; 49: 237-242.

8. Qazilbash AA, Bari A. Sero-diagnosis of human brucellosis among TB suspected patients. J Pak Med Assoc 1997; 47: 243-246.

9. Martin JM, Neches WH, Wald ER. Infective endocarditis: 35 years of experience at a children's hospital. Clin Infect Dis 1997; 24: 669-675.

10. Johnson DH, Rosenthal A, Nadas AS. A forty-year review of bacterial endocarditis in infancy and childhood. Circulation 1975; 51: 581-588.

11. Hoffman JI, Kaplan S. The incidence of congenital heart disease. J Am Coll Cardiol 2002; 39: 1890-1900.

12. Dhawan A, Grover A, Marwaha RK, et al. Infective endocarditis in children: profile in a developing country. Ann Trop Paediatr 1993; 13: 189-194.

13. Bitar FF, Jawdi RA, Dbaibo GS, Yunis KA, Gharzeddine W, Obeid M. Paediatric infective endocarditis: 19-year experience at a tertiary care hospital in a developing country. Acta Paediatr 2000; 89: 427-430

14. Ifere OA, Masokano KA. Infective endocarditis in children in the Guinea savannah of Nigeria. Ann Trop Paediatr 1991; 11: 233-240.

15. Chen SC, Hsieh KS, Wang YJ, Chen YJ, Chi CS. Infective endocarditis in infants and children during the past ten years. Zhonghua Yi Xue Za Zhi (Taipei) 1994; 53: 109-115.

16. Paganini H, Firpo V, Villa A, et al. Clinical study and analysis of risk factors for mortality in 86 cases of infectious endocarditis in children and adolescents in Argentina: 1988-2000. Enferm Infecc Microbiol Clin 2004; 22: 455-461. 
17. Lertsapcharoen $\mathrm{P}$, Khongphatthanayothin A, Chotivittayatarakorn $\mathrm{P}$, Thisyakorn C, Pathmanand C, Sueblinvong V. Infective endocarditis in pediatric patients: an eighteen-year experience from King Chulalongkorn Memorial Hospital. J Med Assoc Thai 2005; 88 (4 Suppl): S12-S16.

18. Bassili A, Mokhtar SA, Dabous NI, Zaher SR, Mokhtar MM, Zaki A. Congenital heart disease among school children in Alexandria, Egypt: an overview on prevalence and relative frequencies. J Trop Pediatr 2000; 46: 357-362.

19. Khongphatthanayothin A, Layangool $T$, Sittiwangkul R, Pongprot Y, Lertsapcharoen P, Mokarapong P. Pediatric heart surgery waiting time in Thailand and its effect on mortality: A cooperative study from Chulalongkorn, Children and Chiang Mai University hospitals. J Med Assoc Thai 2005; 88 (4 Suppl): S23-S29.

20. Asou T, Rachmat J. Pediatric cardiac surgery in Indonesia. Cardiol Young 1998; 8: 437-439.

21. Saxena A. Congenital heart disease in India: a status report. Indian J Pediatr 2005; 72: 595-598.

22. Morris CD, Reller MD, Menashe VD. Thirty-year incidence of infective endocarditis after surgery for congenital heart defect. JAMA 1998; 279: 599-603.

23. Geva T, Frand M. Infective endocarditis in children with congenital heart disease: the changing spectrum, 1965-85. Eur Heart J 1988; 9: 1244-1249.

24. Bhat AW, Jalal S, John V, Bhat AM. Infective endocarditis in infants and children. Indian J Pediatr 1996; 63: 204-209.

25. Sadiq M, Nazir M, Sheikh SA. Infective endocarditis in children incidence, pattern, diagnosis and management in a developing country. Int J Cardiol 2001; 78: 175-182.
26. Van der Meer JT, Thompson J, Valkenburg HA, Michel MF. Epidemiology of bacterial endocarditis in The Netherlands. I. Patient characteristics. Arch Intern Med 1992; 152: 1863-1868.

27. De Gevigney D, Pop C, Delahaye JP. The risk of infective endocarditis after cardiac surgical and interventional procedures. Eur Heart J 1995; 16 (B Suppl): 7-14.

28. Sadiq M, Latif F, Ur-Rehman A. Analysis of infective endarteritis in patent ductus arteriosus. Am J Cardiol 2004; 93: 513-515.

29. Campbell M. Natural history of persistent ductus arteriosus. $\mathrm{Br}$ Heart J 1968; 30: 4-13.

30. Balzer DT, Spray TL, McMullin DO, Cottingham WDO, Canter CE. Endarteritis associated with a clinically silent patent arterial ductus arteriosus. Am Heart J 1993; 125: 1192-1193.

31. Lamas CC, Eykyn SJ. Bicuspid aortic valve - a silent danger: analysis of 50 cases of infective endocarditis. Clin Infect Dis 2000; 30: 336-341.

32. Choudhury R, Grover A, Varma J, et al. Active infective endocarditis observed in an Indian hospital 1981-1991. Am J Cardiol 1992; 70: 1453-1458.

33. Roberts WC. The congenitally bicuspid aortic valve: a study of 85 autopsy cases. Am J Cardiol 1970; 26: 72-83.

34. $\mathrm{Li} \mathrm{W}$, Somerville J. Infective endocarditis in the grown-up congenital (GUCH) population. Eur Heart J 1998; 19: 166-173.

35. Prendergast $\mathrm{BD}$. The changing face of infective endocarditis. Heart 2006; 92: 879-885.

36. Bouza E, Menasalvas A, Munoz P, Vasallo FJ, del Mar Moreno M, Garcia Fernandez MA. Infective endocarditis: a prospective study at the end of the twentieth century - new predisposing conditions, new etiologic agents, and still a high mortality. Medicine (Baltimore) 2001; 80: 298-307. 